\title{
The Differences between Men and Woman in the Labor Market in Albania (Durres Case)
}

\section{Ramiola Kalemi}

kalemi_ramiola@yahoo.com

\author{
Doi:10.5901/ajis.2013.v2n8p272
}

\section{Abstract}

\begin{abstract}
In Albania, between the different regimes, communist and post-communist, the society has been transformed, bringing in this manner various problems, which are still very present, even after 22 years of democracy. The situation is still chaotic even though the democratic models rule the state of Albania. Different problems occurred not only in employment sector, but also in the social status of women, which remains the same. After 90 years, in the labor market, we have had the most improper level of employment in relation to the average of other countries in transition. Reducing the level of employment in the 90 years was a consequence of the decrease of employment in public sector companies. The number of employees in the public sector fell from 850.000 in 1991 to 189.000 in 2001 and 176,000 in 2004. This phenomenon has come as a result of mass privatization of public companies. The end of the socialist regime, the liberalization of prices in close connection with the lack of capital and foreign competition - the measures taken to make the economy competitive in the long run, lead to failure, and so a large number of workers have lost their jobs, including many women. The women employed in the public sector account for 37 percent of the total. The analysis of employment in years indicates that during the period 1993 to 2006, the employment level of women continues to be significantly lower than that of men. This study's main objective is the presentation and evaluation of the current situation in a transparent way in a city, one of the largest in Albania, Durres. Doing these types of analyzes at the end of the trajectory, we took different conclusions that the current situation cannot be changed only with the improvement of legal framework, because the problem does not derive from legal procedures, but those social, and this is the real challenge for our society.
\end{abstract}

\section{Introduction}

During the communist regime, women have benefited from promotional and incentive policies regarding education and employment, also the participation of women in social and political life were stimulated from the party. Although in general the presence of women in political life was considered symbolic, is necessary emphasize that during the period of communism women occupied key positions in decision-making.

Despite that, according to the regime's ideology (communist), the government provided the necessary services to their citizens, such as care for young children in nurseries and kindergartens, community industry health care, elderly care, etc..., which facilitated somehow the work of women. Despite all this, women were responsible in maintaining family household, according to the traditional gender roles set by society. The distribution of family tasks is the cultural approach to the gender roles was marked up that the family work remained largely attributed to their responsibilities.

During the Cultural Revolution and Ideology in Albania, inspired by the infamous Chinese Revolution of Mao Ce Dun, which began in 1966, the regime encouraged women to be more active in social and working life of the country. Such policy tended to have a dual purpose, to overcome the conservatism and compensate for the lack of manpower, because the development of the country required a work force that could not be satisfied only by men.

By the end of 60 years, the government had managed to reverse the situation to the detriment of women, giving "good example" with the appointment in management positions in government and party, which until recently were covered exclusively by men. If we refer to rural areas, women constituted about 41 percent of the workforce in 1961 and 51.3 percent in 1983.

Despite the high birth rates in the late 80's in Albania, women comprised about 47 percent of the total workforce in the country, and showed 53 percent of the workforce in agriculture, 43.5 percent in industry, 55 percent in trade, 80 percent in health care and 54 percent in education and culture. In northern areas, in the agricultural sector, women had a much higher percentage.

In 1981, women represented 70.7 percent of the total workforce. In the years of transition, women's participation in the labor market registered a sharp decline. This figure in 2005 is 46.8 percent of the active labor force. The level of unemployment of women in Albania is higher than men. Although women have the same, if not higher degree of education among men, the opportunity offered by the labor market is not the same. The employment situation of women 
is more favorable in the field of public administration, which occupies 56 percent of jobs, while 44 percent is held by men. Managerial tasks in the private sector inequality are very much visible, since only 17 per cent is held by women. This percentage becomes insignificant in some areas, for example, only 2 percent of transportation companies is managed by female managers, while in other areas is seen an increase over the national average. In the services sector, women occupy as much as 25 percent of undertakings carrying on business. While reading the above data, it is clear the gap in employment of women compared to men. The focus on the nature and causes of the changes will be objects of this study. The phenomena mentioned above are also mirrored in the town of Durres. Durres is one of the cities of Albania, from the most affected by the phenomenon of internal migration, which led to the materialization of some multidimensional singularities, leading to an opening, as a result of the resident population to the social phenomena that inevitably accompany the migration. Comparison of culture resides with the people who come from different parts of Albania, which has produced many negative results such as domestic violence, poverty, culture clash, which directly led an imbalance within the family system.

Some consequences have materialized indirectly as a result of these phenomena, and one of them is unemployment, especially among the target group of women. This element is existent since the creation of the history of humanity, although in some societies is seen as problematic, while in others less, influenced by cultural norms and control mechanisms, but also depend on the company itself. To have an overview of the situation in the city of Durres, we analyzed the data regarding the occurrences in question following the comparative method. Is important to highlight that during the years when we analyze these data, the legal framework is quite comprehensive, and therefore the conditions for conducting a survey to understand whether the situation has undergone improvements or remains the same.

\section{Study Methodology}

The study is based on quantitative and qualitative methodology. The quantitative research was based on statistics taken from Institute of Statistic and other institutions, which were available to provide various data on the phenomenon of participation in the labor market of men and women at the local level in the district of Durres. The study was made more concrete by studying the opinions of a group of 100 people, women and men in urban and rural areas through a survey. The research for this study was made between Octobers since December 2011.

This questionnaire aims to collect qualitative data and quantitative data, the questionnaire was conducted among habitant of rural and urban areas, 50 women and 50 men, respectively 25 rural and 25 urban areas for each gender. As far as age, education and employment status of persons, questionnaires were distributed randomly, no default

\section{Analysis of Study Findings}

The first session aimed to gather information about the causes of this phenomenon and the interior and exterior legal framework that determine gender equality in Albania.

In the second sessions the study in focused in collection and interpretation of data gathered from local institutions as the Institute of Statistics, the Regional Employment Office, regarding employment of women in this town and comparison with the employment of men.

In the third session is analyzed the questionnaire that include the perception of the phenomena from people living in rural and urban areas of this town.

\subsection{Analysis of the first session of findings}

The chaos produced by the new economic system comported lack of social protection against persons and vulnerable groups. This phenomenon has affected mainly to boost gender discrimination, to the exclusion of women from the labor market for two main reasons, the low cultural development of society and the economic crisis. Women are often forced to assume the traditional role in the family. Some of the factors that have complicated the position of women are as listed above;

- The glass ceiling. In economics, the term "glass ceiling" refers to "a phenomenon that would build inaccessible occult hindering the achievement of women in managerial positions, regardless of their qualifications.

- Informal work. The Albanian economy is largely agricultural economy, characterized by a high percentage (94 percent) of micro-businesses, which largely product informal activities. In non-agricultural sector are employed 55 percent of the workforces and carry out their activities in black. Nationally, 67 percent of women works in 
agriculture, 87 percent of these are self-employed. The work is concentrated in rural and farm family. The number of people working in the private sector, agriculture, continues to be very high in Albania, about 60 percent of the assumptions. In Albania, the workforce is employed in the following areas: a) agriculture, forestry, fisheries, b) production, c) commerce d, d) construction, e) education, f) health systems, etc...

- Domestic violence and women's employment. In Albanian communities, the traditional relations continued to exist in larger form, than in any other ethnic group in the Balkans. Physical or economic violence, are often encountered in Albania. If we refer to a specific definition of economic violence, would be: "Economic violence (economic abuse) includes behaviors aimed at denying the right of the individual and of economic benefit". Some of these behaviors: denying money, food and basic needs, the refusal to contribute financially, the isolation of women, the obligation to work or the obligation not to work, a situation which aims to improve control and power over the wife / partner.

\subsubsection{The internal and external legislation.}

Gender equality is a fundamental civil right, and a common valor for European Union countries, and therefore a necessary condition for the integration and the achievement of employment and social cohesion of the MSAA (Stabilization Agreement and Association), which Albania signed in June, 2006.

\subsubsection{Changes to the Albanian law after 90-st.}

- The sort of labor relations has led to the drafting of a new "Labor Code" in 1995.

- The Constitution guarantees the right to work, in art. 49 (I):

- The Labor Code was approved July 29, 2003 by Law nr. 9125 and recognizes the right;

- On the employment of women and men

- The protection of women against discrimination in the workplace.

- $\quad$ At the wage and vacation pay

- The values of the labor

- The law of "Gender Equality" (2004).

- SNSES (National Strategy for Economic and Social Development) 2003 and 2004.

- With the Decree of the Council of Ministers on July 1, 1998 no.415, was formed "Women and Family Committee" as an organization that reports to the Council of Ministers.

- The Decree of the Council of Ministers on 15 March, 2001 no. 127 imposed "Some additions and modifications to the Decree of the Council of Ministers of July 1, 1998 no. 415, was formed the" Woman and Family Committee" by changing the name of "Woman and Family Committee" to "Committee for Equal Opportunities".

- By Decision no. 59 of 23.1.2003, the Committee for Equal Opportunity joined the Ministry of Labor and Equal Opportunities.

- With the entry into force of Law 9198, dated 01.07.2004 "On gender equality in society", was created the Committee for Gender Equality.

- With the Decision number 127, dated;

- 03.15.2001 was created the "Counsel for Equal Opportunities" with the main task: "The development of gender policies."

- With the approval by Parliament of the Electoral Law on, June 17, 2008 (Elections Code of the Republic of Albania, Law no. 10019, and dated 12/29/2008) has been institutionalized gender equality, to claim a share of 30 percent representation for women in the decision making institutions, either in legislative, executive and judiciary organs.

\subsubsection{International agreements ratified}

- The Convention on the Elimination of All Forms of Discrimination against Women (CEDAW). The Albanian government has ratified this Convention in 1993.

- Beijing Declaration in 1995.

- MDGs (Millennium Development Goals), signed in September 2000. 
- A Beijing +10 , a decade after the Beijing Declaration, and was re-evaluated the period to revised decentralized. No annexes of the Platform for Action.

- The conventions of 'ILO

- The Convention of ILO no. 100 "Equal wage", 1951, states that women and men should receive the same salary. This convention is been ratified by 137 countries, including Albania, too.

- Convention no. 111 of 1958 on Discrimination (in recruitment and employment) concerning equal treatment, including access to jobs and working conditions. This convention has been ratified by 130 countries, including Albania, too.

- Convention no.183, 2000, the protection of motherhood. Albania has ratified this convention, although the framework is complete, in fact, there are of 'gaps in the implementation of these policies and legislative framework.

\subsection{Analysis of second study findings.}

\subsubsection{The analysis of the situation in the city of Durres.}

Between 2006 and 2009 there is an increase in population number, while in 2010 it is noticed a decrease, this phenomenon occurs on the same ratios for both sexes. Another important element during these years is that the ratio of men to women is almost the same, with the exception of 2005 in which the female sex increases numerically.

Working age population (2005 - 2010). Working age population in total, in percentage, in the district of Durres, consists of $49 \%$ of the total population, where women make up $25 \%$ while the percentage males $26 \%$, setting a difference of $1 \%$.

Labor Force $(2005$ - 2010). The division between the genders in the workforce, in reference to the definitions, belonging to persons employed and unemployed, the female is always numerically less present in the communes and municipalities. In 2010 there is a decline as a result of the decrease of the population both for men and for women. The labor force represents $50 \%$ of the population over the past 5 years although women are represented only in $20 \%$, even though compose $51 \%$ of the total population in this region and $25 \%$ of $49 \%$ of the working age population which is $1 \%$ less than men who make up $26 \%$ to $49 \%$.

The activity rate from 2005 - 2010 divided into Municipalities and Communes according to gender subdivision. Women are less active in both communes, and municipalities. The phenomenon which is more visible in communes is that the female activity is higher than in the municipalities.

Women constitute $27 \%$ to $33 \%$ of the total, and men constitute $40 \%$ of this $33 \%$. So there is a big difference.

Total employment in division for Municipalities and Communes for years 2005 to 2010. Women hold fewer and fewer places not exceeding 10,000 in the municipalities and communes.

In 2010 the number of women in the municipalities has a tendency to increase compared to other years, with the exception of 2005, which is even higher than 2010 . While the opposite occurs in the municipalities, women's employment in 2010 goes down from previous years. In the period between 2005 and 2010, we estimate that total figures are the following streams: Women constitute $19 \%$, while men make up $31 \%$ of total employees that is $50 \%$. So do not even represent half of total employees. Women occupy $25 \%$ of total workplaces, while the men reached a percentage higher than the level of employment.

Unemployment rate $(2005$ - 2010). Women constitute $44 \%$ from $32 \%$ of the total, a number that indicates the extent of unemployment in the district of Durres, and males $24 \%$ to $32 \%$.

Employment in the institutions of the District, municipalities and communes (2005 - 2010). Women hold only $19 \%$ to $81 \%$ of the total number of public sector employees. In this way, with these data, it is analyzed not only the participation of women in the labor market in the district, but also the rate of participation in leadership positions in public institutions.

Regarding the employment in various sectors, employment for women is lower in trade and construction, which have been most profitable sectors for these 5 years, respectively:

- Construction Sector. What is noticed is the increased participation of women over the past three years in construction, but still represents only $12 \%$ of the total in the last 5 years.

- Commercial Sector. The participation of women is still low because they take only $29 \%$ of jobs in this sector.

- Meanwhile, two sectors that are dominated by women are health and education

- Education Sector. Compared to other sectors, the education sector is characteristically and historically 
"dominated" by women. This, in fact, due to the nature of the profession that offers the opportunity to spend more time with the family. In this sector, women constitute $41 \%$ of total employees during the years 2005 to 2010. While there is an increase in the number of employees in 2010.

- Health Sector. As in the field of education in health care, women are also well represented, accounting in $45 \%$ of the total. This trend has been constant for three years.

- Regarding the position held in different workplaces we can see that;

- Legislators, senior executives, and senior officers for the years (2005 - 2010).

- A discrimination that has characterized the pathway of women in different societies, but especially in ours, where their role has been well-default, belong to the service of the family, neglect and preventing their participation in the social life of the society. The massive element that has affected this was lack of women in management position, excluding them from decision-making process. Women occupy a total of $26 \%$ of the total management positions until 2008 in which there is a drop, even if there is a significant difference in 2009 and 2010.

- Specialists and Technicians in the workplace. In reference to the positions of technicians and specialists, we will see that the percentage increases, even if the difference is not significant. Participation of women comes to $38 \%$ in total and was growing progressively in the years 2009 and 2010 , but at the same time was increased the total, indicating that growth is general and not only for women in these positions.

\section{Analysis of Third Study Findings}

\subsection{The questionnaire.}

The questionnaire was attended by women and men in urban and rural residents, who have provided the following responses.

\subsection{The generality of the respondents.}

- Age. The survey was conducted mainly to people belonging to the age group $25-54,30 \%$ of respondents in the age group between 15 - 25 years belong to the male population in the rural area, 27\% of urban women, $23 \%$ women in rural areas and $20 \%$ for males in urban areas.

$30 \%$ of respondents in the age group between 25 - 53 years belongs to women living in urban area, $26 \%$ of men in urban areas, $20 \%$ women in rural areas and $24 \%$ of males in areas urban.

$40 \%$ of respondents of the age group between $55-64$ years belongs to women living in rural area, $30 \%$ men of rural areas, $20 \%$ men of rural areas and $10 \%$ for women in urban areas.

- Level of education. Regarding the educational level of respondents, most of them are in possession of a diploma of high school. Men and women with an average level of education; they have a level of education of 8 years, which is the same for both women and men in both areas, urban-rural.

Primary education, four years, $40 \%$ of respondents belong to men living in rural area, $36 \%$ of women of rural areas, $9 \%$ of men in urban areas and $14 \%$ for women in urban areas.

Cycle of eight years, $36 \%$ of respondents belong to men living in rural area, $32 \%$ of women of rural areas, $14 \%$ men in urban areas and $18 \%$ for women in urban areas.

Cycle of secondary school, $26 \%$ of those surveyed population belongs to both men and women in rural areas of rural men in urban areas while $22 \%$ of women in urban areas.

Universities, $45 \%$ of respondents belong to women in urban areas, $44 \%$ for men living in urban areas, the 'men of $11 \%$ to rural areas while the number is 0 for women in rural areas.

Postgraduate cycle, $57 \%$ belongs to the males of the urban women and $43 \%$ of urban area, the number is absent for males and females of the rural area.

- Employment. Most are employed in public administration, women and men living in more urban areas.

Worker in public administration, $45 \%$ of employees are men belonging to urban areas, $26 \%$ women of the urban area, $23 \%$ of rural males and $6 \%$ of rural women.

Employed in the private sector, $53 \%$ of employees are men belonging to rural areas, $10 \%$, women of urban area, $32 \%$ males in the urban area and $5 \%$ of rural women.

Self-employed, $52 \%$ of employees are women belonging to rural areas, $18 \%$, women of urban area, urban 
area of $4 \%$ males and $26 \%$ of rural males.

Unemployed, $53 \%$ belongs to women in rural areas and $47 \%$ belongs to women in urban areas.

In retirement, $50 \%$ belongs to the males in urban areas, $25 \%$ belongs to both women in urban areas, that the males of the rural areas.

\subsection{The responses of 'questionnaire.}

In this session we will analyze the questions and answers of the respondents taking each question in it.

It is observed that residents in rural and urban think that women in different sectors are equal to the male presence. This is also thought by some of the women interviewed. Statistically, 13 women have this perception in rural areas and 6 women in urban areas have answered yes, while most of the women said no, 12 respectively in rural area and 19 in urban areas. For males, greater response is yes, in fact, it shows the responses given, 19 and 15 in rural areas and urban.

From the responses it is perceived that there is a difference in the perception of this phenomenon in both rural and urban in that the level of participation of women in social life.

The reasons why the interweavers think women are not equally represented as men to internal labor market are;

1. Mentality, prevailing mainly among women residing in urban areas,

2. The family permission, maternity

3. Meet the requirements

4. The lack of opportunity, conditions

5. The lack of information

6. For lack of legislation

\subsection{The question "Are you aware of any law or other regulations to protect the rights of women"}

People have opted in these ranking answers;

1. "No" and the most common answer given by men and women in rural areas.

2. "The Constitution" and most commonly provided by men and women living in urban area.

3. The "Law gender equality "is known women residents in urban areas.

4. "Code of family" and recognized by most women living in the urban area.

5. "Labor Code" have opted more women living in urban areas.

\subsection{Regarding the question "Are you aware of international legislation to protect the rights of women".}

The "No" is the most common answer given by men and women in rural, while the best answer chosen by the women residing in urban areas is "Card of Human Rights".

In general, the opinion "no" is given by $64 \%$ of males and especially of the rural area who answered this option in 37\%. The answer "Card of Human Rights" by 25\%, "CEDAW" 7\% and Platform for Action in Beijing only 4\%. From the answers it can be seen that respondents do not have good knowledge of legislation protecting the rights of women in our society.

When asked "It affects the reproductive role (births, care for children and other family members, domestic work) of women's participation in the labor market," they answered "Yes" majority men and women living in urban areas, the opposite has been said by those resident in rural areas. Nearly $58 \%$ answered "Yes" that is divided into $17 \%$ of women in the urban area, followed by $16 \%$ of the urban males, $9 \%$ women in rural areas and $8 \%$, males from rural area.

The answer "No" has been answered by a total of $42 \%$ that is divided, $19 \%$ of males from rural area, $18 \%$ of rural women, $7 \%$ of the urban area from the males and $6 \%$ of women from urban area.

The reason why most interviewed have answered "No " is "discrimination because of gender" $35 \%$, among which $19 \%$ males in urban areas, $24 \%$ women urban areas and $7 \%$ of female rural areas.

The "limited spare time," represents $28 \%$ of responses, virtually divided into $18 \%$ by males in urban areas, $17 \%$ by males in rural areas, $9 \%$ from females and $6 \%$ in urban areas than rural areas.

The option "poverty" was given by $10 \%$ of respondents, divided into $25 \%$ of males from rural area, $17 \%$ of the urban area from the males and $8 \%$ from females of the urban area.

"Lack of social infrastructure" was given by $10 \%$ of respondents divided by males in $25 \%$ of the rural area, $17 \%$ of 
the urban area from the males from females and $8 \%$ of the rural area.

"Discrimination on grounds of motherhood" and was given by $17 \%$ of people, respectively, $25 \%$ of the urban area of females, males $10 \%$ of the urban area and $15 \%$ females from the rural area.

When asked, "You pay social contributions and health insurance," people who do not pay social contributions and health insurance are concentrating mostly in rural areas and are mostly women. $66 \%$ expressed that does not pay health insurance, $31 \%$ of the urban area are males, $25 \%$ are males of the rural area, while $26 \%$ are women of the urban area and $25 \%$ are women the rural area.

The answer 'no' has been answered by $34 \%$ of respondents, almost $37 \%$ of rural women, women $29 \%$ of the urban area, $23 \%$ of rural males and' $11 \%$ of males, the urban area.

\section{Conclusions}

Gender equality is a necessary requirement for any society that has as its purpose the development of a democratic system through the principle of equality and justice in society. We cannot affirm the absence of favorable changes, because in the context of negotiations and discussions have entered the odds of positive discrimination of $30 \%$ participation in public administration to enable more women saying sadly that this and the only way in which this agreement can be fulfilled in Albania. During the study, which has been realized in a circle that ever has been reduced, there was always the same phenomenon, discrimination against women that exists above the legislative framework.

- There is a gap in employment of women and men.

- The women have fewer employment opportunities, even if they pose a greater proportion or equality in numbers with men in the Albanian population.

- Women are less represented in society and are often identified in the housewife role, even if their level of 'education is higher than men.

- Unemployment is higher in women than in men.

- The long-term unemployment is more present in female gender than in male.

- Women are less represented in executive positions and policies.

- Women constitute the majority of workers in the informal sector and do not necessarily get paid contributions and health insurance.

- They are more vulnerable to job loss, in case of reforms.

- They are characterized by the phenomenon of the glass ceiling, have fewer opportunities for job promotion.

- Women are mainly employed in unpaid work.

- It is abused not only physically verbally and emotionally but also economically to a large extent.

- Another conclusion is that in the last five years is thought to have been major improvements, but in fact the situation is nearly the same as the progress is minimal.

These conclusions do not intend to criticize constantly, because in reality the problem of differentiation in the workplace is not only a problem belonging to the less developed or less democratic countries. This is a phenomenon found in many economically developed democratic countries and persisted over time. Problematic are the gender stereotypes that persist independently of what right or wrong.

It is problematic that stereotypes are not only present in the mentality of men but are also that of women too by convincing themselves they cannot do certain types of work. Basically I think it's important to change the way our society perceive the roles and gender stereotypes from the juvenile time, so one solution may be learning models taken at school or in families to change this perception through increased awareness

\section{References}

Kamla Bahsin, Te kuptosh perkatesine gjinore, botim i Qendres se Gruas

OECD, Reaching the Goals in the S-21: Gender Equality and Education, Feb. 1999

Bailyn, (2006). Breaking the mold: Redesigning work for productive and satisfying lives. Ithaca, NY: Cornell.

Korniza analitike e perkatesise gjinore

Hazel Reeves and Sally Baden,Gender and Development: Concepts and Definitions, Prepared for the Department for International Development (DFID), February 2000.

Kroeber, A. L. and C. Kluckhohn, 1952. Culture: A Critical Reviee of Concepts and Definitions.

MIGRATION IN POST-1990 ALBANIA A Facilitator of Socio Demographic Change Triggered by Post-Communist Transformations "Albania is a laboratory to study international migration" (Rusell) 
INSTAT, Femra dhe Meshkuj ne Shqiperi 2006

Federal Glass Ceiling Commission. Solid Investments: Making Full Use of the Nation's Human Capital.Washington, D.C.: U.S. Department of Labor, November 1995

Pereira M., Oltre la differenza:una riflessione sull'autorevolezza, relazione al convegno "Magistratura e differenza di genere" (Firenze, 13 maggio 2005), pubblicato in: www.magistraturademocratica.it/md.php/3/819.

Kroeber, A. L. and C. Kluckhohn, 1952. Culture: A Critical Reviee of Concepts and Definitions.

Udry, J. Richard (November 1994). "The Nature of Gender". Demography 31 (4):561-573. http://www.northeastern.edu/womansstudies /graduate/courses/course_material/men_woman_social/documents/Udry_Nature_of_Gender.pdf.

Haig, David (April 2004). "The Inexorable Rise of Gender and the Decline of Sex: Social Change in Academic Titles, 19452001".http://www.esm.harvard.edu/faculty/haig/Publications files/04InexorableRise.pdf

Raymond Zickel and Ealter R. leaskie, editors. Albania: A Country Study. Washington: GPO for the Library of Congress, 1994.

INSTAT 2006, "Femra dhe Meshkuj 2005"

INSTAT, Perspektivat gjinore ne Shqiperi, Tirane, 2004

Strategjia Kombetare Mbi Barazine Gjinore Dhe Dhunen Ne Familje 2007-2010

Rezultate nga Anketa e Forcave te Punes 2009, Tregu i Punes ne Shqiperi, fq 6, INSTAT

Stategjia sektoriale e punesimit 2007-2013, fq 7

Labour Market Situation in Albania. http://www.google.com/\#sclient=psy-ab\&hl=en\&source=hp\&q=informality+and+woman +employment+Albania\&pbx=1\&oq=informality+and+woman+employment+Albania\&aq=f\&aqi=\&aql=\&gs_sm=e\&gs_upl=5809|703 1|1|7303|8|6|0|0|0|0|319|1572|25.1|6|0\&bav=on.2,or.r_gc.r_pe.,cf.osb\&fp=337d5922ed4f0202\&bie=1280\&bih=894

http://www.mfa.gov.al/dokumenta/lista\%20e\%20konventave\%20te\%20ilo-s.pdf

Blau \&Kahn, 2006, Boraas \& Rodgers, 2003, Gabriel, 2005, Light\&Ureta, 1995; Kontabilitetit Qeveriae SHBA Office (Gao), 2003.

http://www.un.org/womaneatch/dae/cse/GMS.PDF

http://data.un.org/CountryProfile.aspx?crName=ALBANIA

http://siteresources.worldbank.org/PGLP/Resources/Albania_Labor_market_assessment_Albanian.pdf,

http:// www.instat.gov.al

http://eeas.europa.eu/delegations/albania/documents/eu_albania/al_rapport_2011_en.pdf

http://siteresources.worldbank.org/PGLP/Resources/Albania_Labor_market_assessment_Albanian.pdf,

http://www.mpcs.gov.al/dpshb/images/stories/files/kodet/3.3.1._Kodi_Punes.pdf

http://www.oecd.org/dataoecd/33/2/40692452.pdf

http://www.issh.gov.al/index.php?option=com_content\&viee=article\&id=55:perfitimet-nga-dega-e-sigurimit-te-barrelindjeve\&catid=38 :perfitues\&ltemid=58

http://www.mpcs.gov.al/dpshb/images/stories/files/kodet/3.3.1._Kodi_Punes.pdf

http://siteresources.worldbank.org/PGLP/Resources/Albania Läbor market assessment Albanian.pdf, Njesia e Sektorit te Zhvillimit Njerezor Rajoni i Europes dhe Azise Qendrore, Shqiperia: Nje vleresim i varferise, Dokument Bankes Boterore, 5 Nentor 2003.

http://www.mpcs.gov.al/dpshb/images/stories/files/kodet/3.3.1._Kodi_Punes.pdf

http://www.punesimi.info/legjislacioni/Ligj\%20Statusi\%20i\%20Nepunesit\%20Civil.pdf

http://www.osce.org/sq/albania/36683

http://www.instat.gov.al/graphics/doc/doenloads/publikime/2010/Femra\%20e\%20meshkuj\%202008.pdf

http://epub.uni-regensburg.de/14097/1/brunn1.pdf

http://sru.soc.surrey.ac.uk/SRU16/SRU16.html

http://www.northeastern.edu/womansstudies/graduate/courses/course_material/men_woman_social/documents/Udry_Nature_of_Gende r.pdf. 